\title{
Limites e avanços da política de permanência: implicações para afetos e vivências no ensino superior
}

\author{
Limits and advances of permanence policy: implications for affections \\ and experiences in higher education
}

Adélia Augusta Souto de Oliveira ${ }^{1}$

Lucélia Maria Lima da Silva Gomes ${ }^{2}$

\begin{abstract}
RESUMO
A assistência deve ser um instrumento de promoção de justiça social e enfrentamento às desigualdades históricas, no contexto da educação superior brasileira. Observam-se, por meio das práticas de sua implantação, os afetos e vivências (re)produzidos nesse âmbito. A presente proposta objetiva refletir, criticamente, a inserção da Política Nacional de Assistência, na universidade pública federal brasileira, seus afetos e vivências políticas. Para tanto, recorre à experiência profissional da Psicologia, nesse novo campo de atuação, a partir da perspectiva vigotskiana. Observa-se uma melhoria no nível de acesso, com a amplitude e a diversidade de estudantes na universidade, com os programas e ações governamentais, no período de 2001 a 2012 . Desafios que, ainda, apresentam-se na sua permanência, obtenção de sucesso, vivência de afetos potencializadores, na superação da fragmentação dos campos de saber e de ênfase em ações compensatórias e assistencialistas. Conclui-se que demarcar as fragilidades econômicas pode reafirmar estigmas que se sobrepõem ao sujeito, ativo no estabelecimento de encontros afetivos e (com) vivências potencializadores. A Psicologia deve, portanto, refletir sobre as práticas emancipadoras desenvolvidas no contexto da política de permanência, a partir da concepção de sujeito ético-político, produzido por meio da apropriação e transformação das práticas culturais, mediadas nas relações sociais (com)partilhadas no processo histórico vivenciado.
\end{abstract} \begin{abstract}
Assistance should be an instrument for promoting social justice and coping with historical inequalities in the context of Brazilian higher education. Through the practices of its implementation, in this text the affections and experiences reproduced in this context are observed. The present proposal aims to critically reflect on the insertion of the National Assistance Policy, in the Brazilian federal public universities, moreover on its affections and political experiences. For this, it uses the professional experience of Psychology in this new field of action, from a Vygotskian perspective. The results show that government programs and actions improved the level of access, with the breadth and diversity of students in the university from 2001 to 2012 . However, there are challenges that remain in their permanence, as well as in obtaining success, experiencing potential affections, overcoming the fragmentation of fields of knowledge, as well as of emphasis on compensatory and welfare actions. The results also show that to single out the economic fragilities can reaffirm stigmas that dim the subject as an active individual in the establishment of affective encounters and empowering (co-)existences. Psychology must, therefore, reflect on the emancipatory practices developed in the context of permanence politics, based on the conception of ethical-political subject, produced through the appropriation and transformation of cultural practices, mediated in the social relations (co-)allocated in the process historical experience.
\end{abstract}

\footnotetext{
${ }^{1}$ Docente do Programa de Pós-graduação em Psicologia, Universidade Federal de Alagoas, Brasil. E-mail: adeliasouto@ip.ifal.br.

${ }^{2}$ Discente do Programa de Pós-graduação em Psicologia, Universidade Federal de Alagoas. Email: lucelia.silva@proest.ufal.br.
} 
Palavras-chave: Psicologia Sócio-histórica, Assistência ao estudante. Ensino superior.

Keywords: Socio-historical Psychology. Student Assistance. Higher education.

\section{Introdução: inquietações ao diálogo}

De acordo com o Fórum Nacional de Pró-reitores de Assuntos Comunitários e Estudantis (Fonaprace), ao mesmo tempo em que a universidade busca gerar, sistematizar e socializar "o conhecimento e o saber, formando profissionais e cidadãos capazes de contribuir para o projeto de uma sociedade justa e igualitária" (FONAPRACE, 2007, p. 4), abriga contradições; reflexo da sociedade na qual está inserida. Nessa direção, o entendimento das políticas públicas voltadas para a educação está vinculado à compreensão do processo sócio-histórico de construção da universidade brasileira, marcado por forte traço elitista (PEREIRA; MAY; GUTIERREZ, 2014).

$\mathrm{Na}$ busca de romper com esta concepção de ensino voltada para uma minoria, a partir do ano 2000, políticas públicas, com o discurso de democratização da universidade, surgiram como projeto de combate às desigualdades no ensino superior e na sociedade. Sua materialização, no cenário brasileiro, se deu através de mecanismos de acesso à educação superior, tais como: o Fundo de Financiamento Estudantil - Fies (2001) e o Programa Universidade para Todos - ProUni (2005), ambos voltados para a iniciativa privada; o Programa de Apoio a Planos de Reestruturação e expansão das Universidades Federais - Reuni (2007), o Sistema de Seleção Unificada - Sisu (2010) e a Lei de cotas (2012), voltados para o ensino superior federal. O Reuni é apontado como responsável pelo processo de interiorização e aumento do número de vagas no ensino superior federal (FONAPRACE, 2019).

De acordo com dados do Fonaprace, as políticas direcionadas ao âmbito público, como o Reuni, Sisu e a Lei de Cotas, propiciaram mudanças no perfil discente das instituições públicas federais, bem como reforçaram a demanda por assistência estudantil (FONAPRACE, 2016; 2019). Hoje a universidade brasileira se apresenta feminina, mais popular e negra, em decorrência do processo de democratização do acesso, que teve como proposta reduzir o caráter elitista da educação superior. 
Conforme Pan e Zonta (2017, p.36) "nesse cenário, os discursos de inclusão protagonizam os novos modelos de gestão que passam a ser difundidos nas universidades brasileiras em nome de sua democratização”. Para as autoras, políticas que proporcionem "transformações nas histórias de desigualdades sofridas pelos grupos excluídos do ensino superior" (PAN; ZONTA, 2017, p. 37) apresentam-se como basilares no cenário brasileiro.

No entanto, Pereira, May e Gutierrez (2014) tecem críticas ao Reuni e apontam que o Programa se configurou mais como expansão do que democratização do acesso. Democratizar implica possibilitar o acesso e efetivar a permanência na universidade, com investimentos relevantes nesse âmbito.

Ressalta-se que a temática da permanência na educação superior já vinha sendo abordada no debate e em pesquisas realizadas em 1996 e 2003/2004, pelo Fonaprace. Na primeira delas, intitulada "I Pesquisa do Perfil Sócio-econômico e Cultural do Estudante de Graduação das IFES Brasileiras", apontou que, na universidade, 44,29\% de estudantes têm origem familiar nas "categorias C, D e E”, o que representava uma demanda real e potencial para a assistência estudantil, sendo esta a responsável pelas ações de permanência nas IFES (FONAPRACE, 1997).

O resultado dessas pesquisas, em 2007, subsidiou a criação, através da Portaria $\mathrm{n}^{\circ} 39$, do Ministério da Educação, do Plano Nacional de Assistência Estudantil (PNAES), sancionado em 2010, através do Decreto 7.234, transformando-se no Programa Nacional de Assistência Estudantil, permanecendo com a mesma sigla, PNAES. Com prioridade para estudantes de baixa renda, o Programa é considerado um importante instrumento de fortalecimento do processo de democratização das IFES, através de ações de permanência em diversas áreas, conforme necessidade apresentada pelo corpo discente da instituição (BRASIL, 2010).

Ao tratar da "necessidade apresentada pelo corpo discente da instituição" supõe-se que a proposta, na prática, possui caráter ampliado, cabendo a cada instituição delimitar o foco de atuação e intervenção. No entanto, Santiago (2014, p.8) aponta que a assistência estudantil no Brasil "apresenta uma concepção limitada, fragmentada e focalizada nos segmentos sociais mais empobrecidos da 
população, haja vista a referida política adotar a lógica do menor recurso orçamentário para o maior quantitativo de atendimento".

Sabe-se que a assistência estudantil, através das ações de permanência, criadas nas (IFES), proporciona suporte ao estudante. No entanto, sua materialização apresenta contradições, conforme apontado na literatura (LEITE, 2012; SANTIAGO, 2014; LEITE, 2015; BRAGA, 2018).

Vejamos algumas das inquietações que demandam resposta: é possível pensar que o ensino superior, através das políticas de democratização, apresenta um horizonte aos sujeitos de modo fragmentado e deficitário? Estão sendo ofertadas as ferramentas adequadas ao sujeito da política, de maneira que, através da educação, a inclusão social ocorra? Ou se trata apenas de uma abertura de possibilidades, do descortinar o acesso ao ensino superior, seguido de aprisionamento de afetos e vivências? Que reflexões e intervenções realizam as equipes de assistência estudantil sobre o contexto de atuação, especialmente a Psicologia, de maneira que contribuam para a permanência e inserção dos estudantes?

Essas são questões importantes para os profissionais, mormente os profissionais de Psicologia que compõe as equipes de assistência estudantil nas IFES. Nesse sentido, faz-se necessário refletir sobre a política de permanência no ensino superior federal e as implicações dela para a prática e o sujeito da política.

A presente proposta objetiva refletir, criticamente, sobre a inserção da Política Nacional de Assistência na universidade brasileira, os afetos e vivências políticas que suscita para o estudante, a partir da experiência profissional da Psicologia, na assistência estudantil, no âmbito das Universidades Públicas Federais de Ensino Superior, no Brasil, tomando como referência a perspectiva vigotskiana. Defende-se a concepção de sujeito sócio-histórico e de prática emancipadora (SAWAIA, 2009).

\section{Descortinando a assistência estudantil: reflexões para a atuação afetivo-política}

Nas IFES, a assistência estudantil é conduzida, majoritariamente por próreitorias (CÊEPDA, 2018) que podem ter sido criadas devido à força da demanda pela assistência estudantil e as suas repercussões nas mudanças gerenciais da 
universidade (MACHADO; PAN, 2014). Estes setores devem se responsabilizar pela criação de programas ou estratégias na instituição, no intuito de propiciar suporte “[...] às necessidades identificadas por seu corpo discente” (BRASIL, 2010). As pró-reitorias possuem ainda, como referência principal o Decreto 7.234 (PNAES) dando respaldo a regulamentos, estatutos e ações formulados nesse contexto.

O PNAES se fundamentou nas vozes dos discentes das instituições federais vinculadas à Andifes ${ }^{3}$, as quais foram apresentadas nas pesquisas realizadas pelo Fonaprace, desde 1996. Nessas pesquisas foi possível identificar o perfil estudantil das IFES, bem como identificar demandas consideradas como dificultadoras da permanência na universidade.

Como resultado, o PNAES apresentou, em seu texto, dez áreas estratégicas que podem ser desenvolvidas pelas instituições: moradia estudantil; transporte; alimentação; atenção à saúde; inclusão digital; cultura; esporte; creche; apoio pedagógico; acesso, participação e aprendizagem de estudantes com deficiência, transtornos globais do desenvolvimento e altas habilidades e superdotação. As instituições, ao desenvolver tais ações, de acordo com o Decreto 7.234, devem também considerar as especificidades, as áreas estratégicas de ensino, pesquisa e extensão da IFES (BRASIL, 2010).

É nessa direção que Vasconcelos (2010, p. 609) afirma que a assistência estudantil

transita em todas as áreas dos direitos humanos, compreendendo ações que proporcionem desde as ideais condições de saúde, o acesso aos instrumentos pedagógicos necessários à formação profissional, nas mais diferentes áreas de conhecimento, o acompanhamento às necessidades educativas especiais, até $o$ provimento dos recursos mínimos para a sobrevivência do estudante, tais como moradia, alimentação, transporte e recursos financeiros.

\footnotetext{
${ }^{3}$ A última pesquisa intitulada V Pesquisa Nacional de Perfil Socioeconômico e Cultural dos(as) Graduandos (as) das IFES, realizada em 2018 pelo Fonaprace, colheu dados das 63 universidades federais e do Centro Federal de Educação Tecnológica de Minas Gerais e do Centro Federal de Educação Tecnológica Celso Suckow da Fonseca, do Rio de Janeiro, totalizando 65 IFES. O mesmo ocorreu com as pesquisas anteriores, variando o número total de instituições participantes a cada ano.
} 
Compreende-se que a assistência deve ser um instrumento de promoção de justiça social e enfrentamento às desigualdades históricas, no contexto da educação superior brasileira, de maneira que se diminuam as contradições históricas presentes no social. No entanto, de acordo com Dutra e Santos (2017) a assistência estudantil se apresenta sob a perspectiva de diversos olhares e discursos, dentre estes: concessão (favor) versus direito; universalidade versus seletividade; a disponibilidades de recursos mínimos (necessidades básicas) versus integralidade das ações. Tais olhares podem implicar na produção de práticas nem sempre condizentes com o processo de inclusão, no contexto educacional e social.

É o que se observa, por exemplo, no recorte de renda apontado no Decreto 7.234. Sabe-se que os dados das pesquisas do Fonaprace, que buscam reforçar a inserção da política de permanência, são coletados dos estudantes das IFES. No entanto, no texto do PNAES e na sua materialização nas IFES, as ações voltamse para estudantes de baixa renda, regularmente matriculados em cursos de graduação presencial. Tem prioridade o estudante oriundo da rede pública de educação básica, ou com renda familiar per capita de até um salário-mínimo e meio.

Tal afirmação é justificada pelo Fonaprace (2019, p. 32) da seguinte maneira:

Não obstante parta de uma percepção ampla das vulnerabilidades e busque sempre captá-las no público observado, neste relatório são recorrentes as análises relativas à variável de recorte "renda familiar mensal per capita”. A razão para tal encontra-se no próprio PNAES. O Programa define o público alvo das políticas por ele financiadas através da chave de renda familiar mensal per capita de "até um e meio salários mínimos".

$\mathrm{Na}$ prática, é possível identificar outro recorte: por se tratar de recurso financeiro limitado destinado às IFES, anualmente, nem todos os estudantes que possuem este perfil apontado pelo PNAES são incluídos nos programas da assistência estudantil de auxílios financeiros. Apenas os mais necessitados, que participaram de avaliação socioeconômica, poderão ter acesso ao recurso sugerindo estabelecimento de um ranking de classificação socioeconômica. 
Nesse sentido, afirma Leite que

\begin{abstract}
A inserção de políticas focais, fragmentadas e residuais, propaladas nos vários subprojetos apresentados pelas universidades públicas brasileiras, a partir de 2007 (nas federais, em concomitância com a incorporação do Reuni, e nas estaduais, que anteciparam o "modelo" federal), sob o vago título de "Acesso e Permanência", na verdade se consubstancia em poucas esmolas a serem disputadas por muitos (2012, p. 456).
\end{abstract}

$\mathrm{Na}$ contramão da integralidade das ações, Leite (2015) sugere que a assistência estudantil nas universidades parece caminhar para um perfil focalizador, compensatório e assistencialista, pois vem se materializando nas IFES através do repasse de auxílios financeiros os mais diversos, acompanhados por diferentes modalidades de bolsas. As ações geralmente recaem nas áreas de moradia, alimentação e transporte (SANTOS et al., 2015).

Para Rocha et al (2017) as políticas não proporcionam

\begin{abstract}
um tratamento que contribua para sua permanência e sucesso acadêmicos, gerando frustrações para esses sujeitos e, não raro, para suas famílias ou comunidades inteiras. Assim, ao garantir somente o acesso e não a permanência, isto devido ao fato de não se garantir um ensino que permita suprir possíveis defasagens, se reforça a desigualdade social da sociedade brasileira, mantendo e sustentando um arbitrário cultural onde o sujeito segue culpabilizado pelo seu desempenho e pela posição que lhe é atribuída numa estrutura hierarquizada e injusta (p. 243).
\end{abstract}

Pontuamos assim, uma pseudo-inclusão, com reforço das fragilidades, de um lugar de desfavorecidos no contexto universitário, o que sugere um processo de inclusão fragmentado e deficitário. Essa classificação afeta os sujeitos políticos e direciona parte de suas vivências. Definiem-se níveis de vulnerabilidade socioeconômica através do atestado de pobreza, emitido por um profissional de referência da assistência estudantil, geralmente o profissional de Serviço Social, categoria profissional que, segundo Cêpeda (2018), apresenta quantitativo maior de profissionais na política, se comparado aos demais. Esses lugares classificatórios demarcam, em grande parte, as vivências universitárias, em vista 
das ações que enfatizam as diferenças econômicas. Como superá-los afetiva e politicamente?

Ao analisar os sentidos da Política de Assistência Estudantil para os estudantes de uma universidade situada no Paraná, Machado e Pan apontaram que, ao mesmo tempo em que a política garante ao estudante manter-se na universidade, "dá a esse mesmo estudante, por meio dos mecanismos de condução do programa no qual está inserido, um lugar discursivo que é também marcado pela desigualdade que o constitui na universidade: o universitário com ‘fragilidade econômica" (2014, p.194). É esta "fragilidade econômica"

que define o estudante no texto da política, somada ao fomento de outras ações que não focam apenas critérios financeiros (moradia, alimentação, saúde, inclusão digital, apoio pedagógico, etc.), evidencia outras possíveis fragilidades que podem ser lidas no modo de organização e nos diversos eixos de atuação do PNAES e do PROBEM ${ }^{4}$ : fragilidades dos laços que o estudante estabelece com a universidade (frente à possibilidade da evasão) e a fragilidade de sua formação anterior, em escolas públicas (as quais são associadas ao ensino de baixa qualidade) (MACHADO; PAN, 2014, p. 194).

A universidade assim, por ser parte dessa engrenagem social, com suas contradições, também realiza recortes, fragmenta e parece distante de realizar a inclusão social. Ao se negar a vivência de sofrimentos, ética e políticamente perversos, no processo de inclusão-exclusão, suprimem-se direitos e vivência de cidadania (SAWAIA, 2006). Necessário, pois, contemplar a dimensão das emoções vivenciadas, presente em injustiças sociais, opressão, exploração e nãoreconhecimento de direitos.

Com o intuito de alcançar o caráter universal e integral das ações, a assistência estudantil apresenta uma ampla diversidade de técnicos administrativos de nível superior e de nível médio (CÊEPDA, 2018). Dentre as áreas de atuação no nível superior, encontramos profissionais da Administração, do Serviço Social, da Psicologia, profissionais da Saúde, da Nutrição, da

4 O PROBEM - Programa de benefícios econômicos para manutenção, desenvolvido na Universidade Federal do Paraná (UFPR), objetiva garantir a permanência dos estudantes com fragilidade econômica. 
Pedagogia e outros; do nível médio, assistente e auxiliar administrativo, profissionais de saúde e outros.

No entanto, existe discrepância com relação ao quantitativo de assistentes sociais se comparado com outras categorias, o que pode estar relacionado ao foco das ações desenvolvidas na assistência estudantil. É o que confirma a pesquisa realizada por Cêpeda (2018), que identificou um total de 399 profissionais de serviço social, atuando na assistência estudantil das IFES, profissionais responsáveis pela avaliação socioeconômica para acesso aos Programas de bolsas e auxílios. Pouco mais da metade desse total compõe o universo de psicólogos (201), e apenas 60 profissionais de pedagogia estão inseridos na assistência estudantil das IFES. Desse modo, mais uma vez parece que o investimento recai no acesso da categoria discente. Nesse caso, no acesso à bolsa ou aos auxílios financeiros, conforme apontou Leite (2015). A sua permanência, que envolve propostas mais amplas, considerando as outras áreas do PNAES, bem como o acompanhamento sistemático de cada ação, nem sempre tem se efetivado. É oportuno afirmar que, ao considerar as 10 áreas apontadas no Decreto, bem como a diversidade de profissionais, a proposta da assistência estudantil deveria caminhar para uma atuação pautada numa perspectiva multiprofissional e de integralidade das ações.

Um dos impedimentos pode estar relacionado ao número de profissionais disponíveis em cada IFES. Mancebo, Val e Barbosa (2015) tecem críticas ao Reuni, principal instrumento de expansão e interiorização das IFES, e apontam que o Programa não conseguiu atingir seus objetivos, pois o aumento do número de estudantes não foi acompanhado pelo incremento necessário no número de professores e técnicos. Além disso, reforçam que os recursos destinados para a construção da estrutura física foram insuficientes para sua expansão. Esse fato comprometeu a qualidade da vida acadêmica e o trabalho de suporte aos estudantes oferecido pelos servidores técnicos. Nessa perspectiva, tem sido pontuada, pelos coletivos de discentes, a necessidade de ampliar os avanços nas atividades desenvolvidas pelos técnicos das universidades.

Embora os números apresentados por Cêpeda (2018) apontem quantitativo importante de profissionais na assistência estudantil em âmbito nacional, em 
cada IFES ainda existe reduzido quantitativo de profissionais frente às demandas discentes e institucionais, relacionadas à assistência estudantil. Nessa direção, nem sempre as ações realizadas nesse contexto se configuram como multi ou interdisciplinares. Aqui se apresentam dificuldades de ações que superem a fragmentação dos campos de saber e de ações compensatórias e assistencialistas. Desafio que envolve esforço importante da instituição, profissionais, docentes e discentes, no âmbito da intervenção e da formação acadêmica.

A universidade é chamada a modificar o quadro social, marcado historicamente pela desigualdade social brasileira e pelas inúmeras dificuldades em seu enfrentamento. Observa-se que, segundo o Fonaprace (2019), muitas são as dificuldades que interferem na vida e no contexto acadêmico do aluno. Essas são decorrentes da própria vivência em sociedade, ou seja, das ausências e fragilidades do poder público, nos diversos âmbitos da vida política (saúde, educação, cultura, alimentação, moradia). Desta maneira

Para enfrentar muitas destas dificuldades, as IFES dispõem de algum mecanismo de intervenção, normalmente sustentado por decreto presidencial e distribuído entre as dez áreas de atuação do PNAES (alimentação, moradia, transporte, saúde, cultura, esporte, acessibilidade, creche, inclusão digital e apoio pedagógico) (FONAPRACE, 2019, p. 79).

Consideram-se legítimas e necessárias as contribuições das intervenções da assistência estudantil para minimizar desigualdades históricas da sociedade, representadas no contexto universitário. Ao mesmo tempo, a universidade deve assumir prática emancipadora e ser mediadora na construção de um projeto social igualitário, distanciando-se de uma postura substitutiva do papel da rede de saúde e de educação básica, por exemplo.

Defende-se a importância da realização de ações ampliadas que façam frente à evasão e à retenção, tanto no contexto interno, como externo à universidade. Propõem-se a reflexividade para além das demandas do sujeito, na direção de relação dialógica com os inúmeros dispositivos da rede de assistência (os sistemas de saúde, educação, justiça, família), especialmente, no entorno da universidade. Desse modo, importa demarcar o sujeito político e ativo no seu 
processo de humanização (SAWAIA, 2009; SAWAIA; MAGIOLINO, 2016; SAWAIA; SILVA, 2015; VIGOTSKI, 1991; VIGOTSKI, 1993; VIGOTSKI, 1998; VIGOTSKI, 2004). Sujeito esse que, segundo Sawaia (2019, p. 369) apresenta "potencialidade de desenvolvimento mediado pelas intersubjetividades e atividades".

Nesse contexto, cabe aos profissionais da assistência estudantil colaborar com o aperfeiçoamento de políticas sociais, buscando superar mecanismos de inclusão perversa, conforme pontua Sawaia (2009). Sabe-se que

\begin{abstract}
Diante dessa nova configuração no campus, houve também uma inesperada ampliação da procura por psicólogos escolares na educação superior, pressupondo-se que os novos perfis estudantis, aliados às configurações e exigências acadêmicas, iriam requerer desse profissional "tratamento" para os "futuros possíveis e previsíveis" problemas de aprendizagem, defasagens acadêmicas e inadequação social (MARINHO-ARAÚJO, 2016, p. 202).
\end{abstract}

Nessa medida, pode-se reafirmar, erroneamente, um "tratamento", amparado na tentativa de reduzir a evasão e a retenção, que prioriza uma visão individualizadora da problemática e desconsidera a complexidade do contexto na qual ela se insere. O desafio da prática da Psicologia nesse contexto é recente, datado e fruto da implementação das políticas de democratização do acesso ao ensino superior. Cabe aos profissionais de Psicologia, numa perspectiva ampliada e no trabalho em equipe, refletir sobre as demandas recebidas e problematizarem as ações desenvolvidas. Seria urgente considerar, nessa proposta, um sujeito ativo, afetivo e político, consubstanciado nas contradições sociais e históricas da sociedade brasileira. Se assim não o fizermos, podem-se dificultar encontros afetivos e (con)vivências potencializadoras, ratificando práticas mantenedoras do que Sawaia (2009) denominou de sofrimento éticopolítico, processo psicológico-político responsável pela reprodução da desigualdade, oriundo da "relação entre as ameaças provenientes da desigualdade social e as respostas afetivas dos que a ela se assujeitam" (p. 370).

Entende-se, ainda, ser fundamental pensar as estratégias de ensino no âmbito da educação superior, mas longe de propor ações imediatistas, paliativas e românticas. Desse modo, concordamos com Pereira, May e Gutierrez (2014) sobre 
avançar no debate sobre a relação da universidade com a educação básica, espaço de formação e percurso das classes populares, pois "é a partir da consideração de todo o percurso escolar e suas implicações com o ambiente social que podemos compreender de forma mais evidente as desigualdades escolares" (PEREIRA; MAY; GUTIERREZ, 2014, p. 134).

Apresenta-se, assim, um imenso desafio, proporcional ao que pode afetar as vivências universitárias dos estudantes.

\section{Considerações finais: desafios à vista}

Considera-se que as pesquisas realizadas pelo Fonaprace subsidiaram a importante iniciativa de democratização do ensino superior brasileiro, por meio de políticas sociais de enfrentamento à desigualdade social de jovens. Em decorrência, da ampliação do acesso, verifica-se o aumento e a diversidade de estudantes na universidade que precisam permanecer e obter sucesso, superar desafios, próprios das exigências do ensino superior. Caso contrário, podem vivenciar sofrimento psicossocial, com afetos culpabilizadores de fraco desempenho. Demarcar apenas as fragilidades econômicas, no texto da política, podem reafirmar estigmas e fragilidades que se sobrepõem ao sujeito que poderia estabelecer encontros afetivos e (con) vivências potencializadores no ambiente universitário.

Importante ainda, considerar a necessidade de maior apropriação de conhecimentos, questionamentos, reflexões e acesso aos direitos e políticas públicas e sociais, especialmente, no contexto da educação brasileira. Defendemse ações promotoras de vivências universitárias que ampliem nossa humanidade, em contraponto às vivências de sofrimento ético-político, que reverberam e reproduzem exclusão.

Considera-se, por fim, a incumbência dirigida aos profissionais da assistência estudantil de um exercício de reflexividade sobre as práticas desenvolvidas no contexto da política de permanência: pressupor um sujeito constituído sócio-historicamente, por meio da apropriação e transformação das práticas culturais, mediadas nas relações sociais compartilhadas no processo histórico vivenciado. 


\section{Referências}

BRAGA, G. P. de O. Programa Nacional de Assistência estudantil: fundamentos críticos e problematizações. Sociedade em debate, Pelotas, v.25, n.2, p. 25-38, 2018. Disponível em:< http://revistas.ucpel.tche.br/index.php/rsd/article/view/1832/1178>. Acesso em 20/01/19.

BRASIL. Decreto $n^{\circ}$ 7.234, de 19 de julho de 2010. Dispõe sobre o Programa Nacional de Assistência Estudantil - PNAES, 2010. Diário Oficial da União, 20 jul. 2010. Disponível in:< http://www.planalto.gov.br/ccivil_03/_Ato20072010/2010/Decreto/D7234.htm >. Acesso em 20/07/18.

CÊPEDA, V. A. II Pesquisa Nacional do Perfil das Instituições Federais do Ensino Superior para a Assistência Estudantil - um mapeamento de capacidades e instrumentos. Resultados da Coleta 2016. São Carlos: Ideias, Intelectuais e Instituições; FONAPRACE; ANDIFES, 2018.

DUTRA, N. G. R.; SANTOS, M. F. S. Assistência estudantil sob múltiplos olhares: a disputa de concepções. Ensaio: Avaliação e Políticas Públicas em Educação, Rio de Janeiro, v. 25, n. 94, p. 148-181, 2017. Disponível em: $<\underline{\text { http://www.scielo.br/scielo.php?pid=S010440362017000100148\&script=sci_abstr }}$ act>. Acesso em 20/09/18.

FONAPRACE - Fórum Nacional de Pró-reitores de Assuntos Comunitários e Estudantis. I Pesquisa do Perfil Sócio-econômico e Cultural do Estudante de Graduação das IFES Brasileiras. Belo Horizonte, 1997.

Plano nacional de assistência estudantil. 2007. Disponível em:

<http://www.andifes.org.br/plano-nacional-de-assistencia-estudantil-da-andifes/>. Acesso em 05/06/18.

FONAPRACE. IV Pesquisa do Perfil Socioeconômico e Cultural dos Estudantes de Graduação das Instituições Federais de Ensino Superior Brasileiras. Brasília, 2017.

- Relatório da V Pesquisa do Perfil Socioeconômico e Cultural dos

Estudantes de Graduação das Instituições Federais de Ensino Superior Brasileiras. Belo Horizonte, 2019.

LEITE, J. de O. As múltiplas determinações do programa nacional de assistência estudantil - Pnaes nos governos Luiz Inácio Lula da Silva. 2015. 544f. Tese (Doutorado) - Programa de Pós-graduação em Serviço Social, Universidade Federal de Pernambuco, Recife. 2015. 
LEITE, J. L. Política de Assistência Estudantil: direito da carência ou carência de direitos? SER social, Brasília, v. 14, n. 31, p. 453-472, 2012.

MACHADO, J. P.; PAN, M. A. G. de S. Política pública e subjetividade: a assistência estudantil na universidade. Textos \& contextos, Porto Alegre, v. 13, n. 1, p. 184-198. 2014. Disponível em: <http://revistaseletronicas.pucrs.br/ojs/index.php/fass/article/view/15929> Acesso em 23/01/19.

MANCEBO, D.; VALE, A. A.; BARBOSA, M. T. Políticas de expansão da educação superior no Brasil 1995-2010. Revista Brasileira de Educação, vol. 20, n.60, p. 31-50, 2015. Disponível em: <http://www.scielo.br/pdf/rbedu/v20n60/14132478-rbedu-20-60-0031.pdf>. Acesso em 20/09/18.

MARINHO-ARAÚJO, C. M. Inovações em Psicologia Escolar: O contexto da educação superior. Estud. psicol., Campinas, v. 33, n. 2, p. 199-211, 2016. Disponível em: <http://www.redalyc.org/articulo.oa?id=395354131003>. Acesso em 15/06/2018;

PAN, M. A. G. S.; ZONTA, G. A. Acolhimento por pares como prática de formação de psicólogos: Plantão institucional e Rodas de Conversa. In: PAN, M. A. G. S.; ALBANESE, L.; FERRARINI, N. L (org.). Psicologia e educação superior: formação e $(m)$ prática. Curitiba: Juruá, 2017, p. 35-54.

PEREIRA, T. I.; MAY, F.; GUTIERREZ, D. O acesso das classes populares ao ensino superior: novas políticas, antigos desafios. Revista pedagógica, v. 16, n 32, p. $117-140,2014$ Disponível em: <https://bell.unochapeco.edu.br/revistas/index.php/pedagogica/article/view/2726/1 550>. Acesso em 20/10/18.

ROCHA, F. et al. "Colegas de estudo" e a produção de contextos sociais de apoio para universitários com dificuldades de persistência na permanência no ensino superior. In: PAN, M. A. G. de S; ALBANESE, L.; FERRARINI, N. L. Psicologia e educação superior: formação e $(m)$ prática. Curitiba: Juruá, 2017, p. 231-252.

SANTOS, A. S. et al. Atuação do Psicólogo Escolar e Educacional no ensino superior: reflexões sobre práticas. Psicologia escolar e educacional. Campinas, v. 19, n. 3, p. 515-524, 2015. Disponível in: <https://www.lume.ufrgs.br/handle/10183/163620.> Acesso em: 20/06/2018.

SANTIAGO, S. N. A política de assistência estudantil no governo Lula: 2003 a 2010. 219 f. Dissertação (Mestrado em Educação) - Programa de Pós-Graduação em Educação, Instituto de Ciências em Educação, Universidade Federal do Pará, Belém, Pará, 2014.

SAWAIA, B. B. O sofrimento ético-político como categoria de análise da dialética exclusão/inclusão. In: Sawaia. B. (org.). As artimanhas da exclusão: uma análise ético-psicossocial da desigualdade (pp. 97-119). Petrópolis: Vozes, 2006. 
SAWAIA, B. B. Psicologia e desigualdade social: uma reflexão sobre a liberdade e transformação social. Psicologia \& Sociedade, Florianópolis, v. 21, n. 3, p. 364 372, $2009 . \quad$ Disponível em <http://portal.mec.gov.br/arquivos/pdf/portaria pnaes.pdf $>$. Acesso em 15/07/18.

SAWAIA, B. B.; MAGIOLINO, L. L. S. As nuances da afetividade: emoção, sentimento e paixão em perspectiva. In: BANKS-LEITE, L.; SMOLKA, A. L. B.; DOS ANJOS, D. D. (org.). Diálogos na perspectiva histórico-cultural interlocuções com a clínica da atividade. Campinas: Mercado de Letras, 2016, p. 61-86.

SAWAIA, B. B.; SILVA, D. N. H. Pelo reencantamento da Psicologia: em busca da positividade epistemológica da imaginação e da emoção no desenvolvimento humano. Cad. CEDES [online], Campinas, v.35, n.spe, p .343-360, 2015. Disponível em:< http://www.scielo.br/scielo.php?pid=S0101-

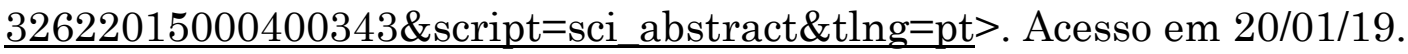

VASCONCELOS, N. B. Programa nacional de assistência estudantil: uma análise da evolução da assistência estudantil ao longo da história da educação superior no Brasil. Ensino Em-Revista, Uberlândia, v. 17, n. 2, p. 599-616, 2010. Disponível in: < http://www.seer.ufu.br/index.php/emrevista/article/view/11361>. Acesso em 10/11/18.

VIGOTSKI, L. S. Obras escogidas: el significado historico de la crisis de la psicologia. Madrid: Visor, 1991. i.

1993. ii.

Obras escogidas: Problemas de Psicologia General. Madrid: Visor, Psicologia da arte. São Paulo: Martins Fontes, 1998.

VIGOTSKI, L. S. Teoría de las emociones - Estudio histórico psicológico. Madrid: Akal, 2004. 